\title{
Chapter 12 \\ Concluding Thoughts on Life Skills Education for Youth
}

\author{
Dana Schmidt
}

\begin{abstract}
This chapter summarizes the answer to the motivating question for this book: "Which life skills are important, for whom, and how can they be taught?" Drawing on research reflected in the preceding chapters, I highlight three broad themes. First, that teaching life skills helps marginalized adolescents in particular but should not put the onus of overcoming marginalization squarely on their shoulders. Second, that consensus seems to be emerging that a cluster of social and emotional skills and cognitive abilities like critical thinking are particularly important for success. Third, that the way in which life skills are taught matters as much as which skills are taught. I also reflect on three big barriers that we need to address if we really want to advance the agenda of life skills. First, governments may not embrace the transformative change we want to see. Second, life skills programs are complex to implement and to measure. Lastly, we cannot ignore the risk of unintended consequences on the path to developing life skills. I suggest that each of these challenges is worth contending with to give youth of today a fighting chance to deal with the expected and as-yet unimagined challenges of tomorrow.
\end{abstract}

Keywords Life skills · Low and middle-income countries $\cdot$ Capabilities approach -Wellbeing

\section{Introduction: Which Life Skills? It Depends}

The key question posed by this volume of work is: "Which life skills are important, for whom, and how can they be taught?" If we look at life skills as the skills "to be able to do life well," which is the simple definition offered by Murphy-Graham and

\footnotetext{
D. Schmidt $(\bowtie)$

Echidna Giving, San Francisco, CA, USA

e-mail: dana@echidnagiving.org
} 
Cohen (Chap. 2, this volume), the answer to the motivating question of the volume is "it depends."

It depends on objective factors, like which individual, at what point in time, and in what place. Skills to do life well will not look exactly the same for a 13-year-old boy living with a pastoralist community in Ethiopia today as they do for an 18-yearold girl with two young children in Honduras, let alone for the same 13-year-old boy in Ethiopia 20 years hence, or, for that matter, for his sister today. Their lives look different so the skills they need will be different, too.

It also depends on subjective factors, like how any of these given individuals define what it means to do life well. Is doing life well about having economic stability? Becoming wealthy? Succeeding in school? Staying healthy? Securing strong relationships? Achieving happiness? Some combination thereof?

Time and again contributors to this volume point out the ways in which life skills education looks different across various contexts and schools of thoughts. For example, Murphy-Graham and Cohen (Chap. 2, this volume) show us in Chap. 2 how different discourse communities have defined different goals for life skills, and therefore emphasized different skill sets. Economists have stressed labor market outcomes and landed on teamwork, communication, problem solving, and the Big 5 personality traits as key skills to foster. For those focused on public health prevention and protection, decision-making, self-knowledge, and resisting peer pressure are paramount. In Chap. 3, Brush et al. (this volume) describe a diversity of frameworks - 40 of which they have coded - each of which have been developed with particular contexts and viewpoints in mind, and which therefore each feature distinct combinations of skills. This set of diversity should not surprise us. As Honeyman et al. (Chap. 6, this volume) stress in Chap. 6, program designers need to undertake a contextualization process that examines which skills to teach in combination with the context in which they will be taught. In the case of youth in Algeria, perseverance and self-motivation stood out as critical skills required for finding a job.

That said, "it depends" is not a very actionable answer to the question posed by this volume. Nor is it all that we can say on the basis of the research presented here. So although it does, indeed, "depend," the research presented in this book points to three broad themes that provide more interesting answers to the question "Which life skills are important, for whom, and how can they be taught?"

1. Life skills are especially important for marginalized adolescents, but should not be used as an excuse to put the onus of creating a life well lived entirely on the individual, particularly not on an individual already marginalized by his or her community. Societal transformation requires more than this.

2. Whether you care most about health outcomes, economic prosperity, or broader empowerment, there are some common denominators with respect to which skills are important. In particular, clusters of social and emotional skills and cognitive abilities like critical thinking stand out as important for success. More specifically, critical thinking skills related to who holds power in society and why emerges as one key to the types of transformational changes that are drawn 
out under the first theme. These common denominators are a good starting point for at least some of the life skills that are likely to matter most.

3. How life skills are taught may be as important, if not more important, than prescribing a very specific set of skills to teach. Given this, the ways in which teachers are prepared to teach life skills and the skills they themselves embody are important pieces of the puzzle.

The remainder of this conclusion unpacks each of these themes in more detail. Drawing from the chapters that precede this one, I highlight some critical takeaways for actors trying to improve the lives of adolescents and identify key unanswered questions for the research community to tackle as well.

\section{Theme 1: Teaching Life Skills Helps Marginalized Adolescents, But Not in Isolation}

The very fact that different discourse communities have articulated the importance of life skills (as highlighted in Chap. 2), multiple frameworks have been developed around life skills (as highlighted in Chap. 3), and countless programs have been designed to teach life skills (as highlighted in Chaps. 5, 6, 7, 8, 9, and 10, to name but a few), lends credence to the idea that adolescents need more than academic skills to "do life well." Brush et al. (Chap. 3, this volume) describe how social and emotional learning programs tend to have a disproportionately large effect on students who are most at risk. This suggests that marginalized adolescents may stand to benefit the most from life skills programs.

At the same time, chapter authors have emphasized the risk that providing life skills programs to marginalized adolescents will put the onus of creating change on the very people who face the greatest disadvantage. One key implication here is that skills alone are not enough. In Chap. 4, DeJaeghere (this volume) points out that the dominant approach to life skills tends to be oriented towards changing the behavior of individuals and placing the responsibility on youth for addressing societal problems that cannot be overcome by individuals. As Murphy-Graham (this volume) articulates in Chap. 7, skills need to be paired with real opportunities for individuals to do something with them, but individuals often face structural constraints to converting their skills into action. These come in the form of personal constraints (sex, intelligence, disability, etc.), social constraints (norms, hierarchies, power relations, etc.), and environmental constraints (infrastructure, resources, etc.). For example, the life skills job training program that Murphy-Graham studied failed to generate employment opportunities for youth because there simply are not many formal work opportunities in Honduras and Guatemala. Furthermore, program participants faced social stigma, sex discrimination, and practical constraints due to the crime and violence in their neighborhoods that limited the success of their job searches.

The second key implication is that the types of life skills that are taught and the way in which they are taught can either uphold the status quo of marginalization or 
be transformative. Unfortunately, most life skills programs are not designed to be transformative. By way of concrete example, in Chap. 4 DeJaeghere (this volume) describes how "considerable literature on girls' education and gender inequalities have raised the concern that educating girls alone cannot create transformative change, yet the renewed focus on life skills for girls is another iteration of seeking education solutions to do so." Underscoring this point, in Chap. 5 Kwauk (this volume) finds that "the dominant normative approach of 'fix the girl, not the system,' is quite pervasive" in sports for development programs. Only 4\% of targeted skills in these programs were constructed in an intentionally transformative way.

All of this suggests the need to change the larger context even as we give people skills and agency to deal with the current system. It also suggests the need to incorporate skills that help youth navigate towards more transformative change, as described in the theme which follows.

\section{Theme 2: Convergence Around Certain Life Skills Domains, with an Emphasis on Critical Thinking}

Researchers and practitioners arrive at the importance of life skills education from multiple perspectives, but regardless of whether they bring a lens of health and wellness, economic prosperity, or broader empowerment, the skills they prioritize include several common denominators. In Chap. 2, Murphy-Graham and Cohen (this volume) consolidate areas of overlap across different discourse communities into the themes of mastery of knowledge, social and emotional competencies, and critical thinking. In Chap. 3, Brush et al. (this volume) cluster skills into cognitive, emotional, social, values, perspectives, and identity domains. They find that social and emotional learning frameworks place the greatest emphasis on the cognitive domain (which includes critical thinking, planning skills, attention control), and the social domain (which includes, e.g. social problem solving, cooperative behavior). Many life skills frameworks also emphasize the values domain (consisting of ethical, intellectual, performance, and civic values) and, to a smaller extent, the emotion domain.

To summarize this in the simplest of terms, there is agreement that youth need to understand and regulate themselves, be capable of relating to others, and know how to interpret the world around them. These capabilities are central to being able to live life well.

If there is one single skill area that the volume draws out as particularly important, it is critical thinking. Youth need higher order thinking skills, including the capacity to be critical of the world and its injustices. They also need to develop problem solving skills that enable them to tackle these injustices. Across several chapters, we see arguments that this type of critical thinking is the key to ensuring that programs are transformative and not merely helping youth better deal with their marginalization. For example, in Chap. 5, Kwauk (this volume) argues that 
youth must have the opportunity to understand the broader structures of power and privilege in which they are embedded. They must learn to decode dominant culture with the aim to transform not only their own experiences in the world, but also the world itself.

This is not just about being better able to understand power structures, but also about getting youth to challenge these structures, including by changing their own perspectives. One example of this comes in Chap. 9, where Sahni (this volume) describes how the Prerna school in India equips students to both understand and change their realities. Sahni's school is about "helping children gain a greater sense of self-awareness, recognize themselves as equal persons, develop agency and voice, and critically examine societal norms and oppressive social structures." Importantly, the schools work not only with the marginalized, but also with powerholders. For example, when it comes to supporting greater gender equality, the school works with boys to shift their "toxic mindsets." Although this is more difficult because boys have something to lose when it comes to relinquishing their power, the example shared in this chapter shows that change can be fostered carefully, respectfully, and effectively.

We see a second example of this in Chap. 8, in which Arur and Sharma (this volume) describe how adolescent boys of lower castes in India are taught critical literacies that help shape their career aspirations. As these boys engaged in documenting their lived realities by video, they were able to critically understand local issues (particularly around sustainable development) and analyze what mattered to them in ways that helped to uncover potential career choices.

A third example comes from Chap. 10, where Pacheco and Murphy-Graham (this volume) describe the ACHME program in Honduras, which aimed to help students make informed decisions about marriage despite the fact that their economic and sociopolitical context constrained the choices available to them and presented them with ideas and values that encouraged early marriage. The program developed critical thinking in students, helping them to understand power relationships, to redirect the flow of these relationships, and to uncover mainstream norms that they assume to be in their best interest even if they are actually harmful. By getting students to think critically, the program sought to increase cognitive dissonance and lead them to shift their thinking in order to reduce inconsistencies in it. This seems to have played out in practice. For example, students developed the capacity to uncover assumptions about gender roles-like the idea that housework is a woman's job that men should not engage in-and began to articulate their dissatisfaction with the status quo.

Even when life skills frameworks and programs include critical thinking, they often leave out some of these important components. In Chap. 5, Kwauk (this volume) argues that the way we conceptualize critical thinking could be expanded so that it captures skills like understanding and recognizing unequal power relations and picking up on unspoken cues. She argues that a "transformative approach would attend to the metacognitive elements of equipping girls with the tools to read, decode, and act upon the opportunity structures around her, as well as the sociological elements of building collective resistance against conditions of inequality." 
This concept of building collective resistance points to the other shortcoming in the way that many life skills frameworks are framed, which is that they focus on developing individual skills that youth can independently enact. The hyper-focus on individuals is arguably a very "WEIRD" view of schooling, applied in Western, Educated, Industrialized, Rich, and Democratic countries. The concept of WEIRD societies was developed by anthropologist Joseph Heinrich and psychologists Steven Hein and Ara Norenzayan. In a 2010 study, they argue that behavioral scientists frequently publish findings that claim to unearth universal truths about human psychology, but these studies draw on research done only with subjects from WEIRD societies, who are in fact frequently outliers when it comes to many dimensions of psychology, motivation, and behavior. Research done on subjects from WEIRD societies is therefore not representative, nor generalizable to the entire human race. One of the differences they point to is the fact that Westerners tend to view themselves as independent, autonomous agents, whereas non-Westerners tend to have a more interdependent view and think of themselves in terms of roles and relationships with others. From this research we can infer that educational interventions designed for students in WEIRD societies are not equally applicable in nonWEIRD societies. In WEIRD societies, an emphasis on individual skills independently enacted might be well-suited to context, but that might not be as helpful to youth in non-WEIRD societies, where there is a greater emphasis on the collective. Yitbarek et al. (this volume) describe this disconnect in Chap. 11 when they demonstrate how the skills that matter most for Afar wellbeing, which include an emphasis on collective and community wellbeing, are not the same as the skills that are covered in the general education curriculum.

In Chap. 4, DeJaeghere (this volume) argues that youth need to develop relational skills. There is a disconnect between teaching life skills to youth as individuals and expecting them to act on these skills independently, and the need to change larger social outcomes like gender inequality, which are societal and not individual in nature. DeJaeghere argues that "The ideas, beliefs, and attitudes that young people practice to live a good life are not individually learned or enacted; they are influenced and enacted in relation to others and their environment." She further argues that a relational approach would rethink both which skills are taught, as well as how they are used. For example, teaching self-confidence does not change the barriers youth face or allow them to be confident in settings that continue to reject them and deny their dignity. I would argue that it's not only how skills are used that matters, but also the way in which they are taught, an idea we turn to in the third theme, which follows.

\section{Theme 3: How Life Skills Are Taught Matters as Much as Which Skills Are Taught}

In the previous section, we examined which life skills appear to be most critical for youth. As much as this book helps point to areas of consensus in this regard, it also suggests that how life skills are taught matters as much as which skills are taught. 
The first insight in this regard is that life skills do not always need to be directly taught. Instead, they can be learned through modeling and through shifts in the way teachers engage their students. As DeJaeghere (this volume) reminds us in Chap. 4, "humans live and learn always in relation to others and their environment." For this reason, students pick up on skills simply by imbibing what they see around them. This is absorbed as much from community members as it is from teachers. Indeed, in Chap. 8 Arur and Sharma (this volume) demonstrate that it was students' personal networks that influenced their career aspirations more than anything they read online or in textbooks.

Honeyman et al. (this volume) argue in Chap. 6 that the best way to teach many life skills is through "student-centered pedagogy that requires students to be involved in research, problem-solving, discussion, and group work." A good example of this type of pedagogy is documented by Arur and Sharma, who describe how adolescent boys in India created videos as a way to better understand the nature of their home environments and how their skills could be harnessed for work within that context.

Some of these shifts in teaching practice that are critical for unlocking life skills could happen without ever stressing what life skills they are building. This is useful because teachers and students might not always be motivated to teach and learn life skills. In the context of Algeria, for example, most youth were more interested in "learning the functional skills they need to get a job and may not recognize initially the important role that soft skills play in this process" (Honeyman et al., Chap. 6, this volume). In Ethiopia, youth picked up on skills for living in a sustainable way in their community through observation and modeling, not explicit instruction where these skills were named for them (Yitbarek et al., Chap. 11, this volume).

The second insight is that helping to develop teachers' life skills is an important path to imparting life skills in youth. As Honeyman et al. (Chap. 6, this volume) point out, "instructors themselves must demonstrate these skills and attitudes in their own lives" in order to model and teach them to students. Although this may involve training teachers in approaches that are far from common within the wider education system, the good news is that teachers themselves stand to gain from learning life skills. As Sahni (this volume) discovers and describes in Chap. 9, the critical conversations about gender and power facilitated at the Prerna school in India were as transformational for instructors as for the students. Similarly, I have seen in my own work how teachers are highly motivated to teach the resilience curriculum developed by the NGO CorStone because the skills they teach are skills they learn and find relevant to their lives. Likewise, Dream a Dream has found in their work in India that one of the most transformative ways to teach life skills is to transform how teachers see themselves and their students, which transforms how they engage with students and what they teach.

The third insight is that promoting stronger relationships could be a means to teaching life skills but also an important end in and of itself. This comes out in Chap. 7, where Murphy-Graham (this volume) describes how the relationships built by youth in the A Ganar program in Honduras was both a capability and a functioning. The supportive network that students developed helped them to overcome 
structural constraints. Similarly, Honeyman et al. (Chap. 6, this volume) highlight "promoting strong relationships between adults and youth and among youth themselves" as one of the best practices for developing life skills. In the Prerna school that Sahni describes in Chap. 9, individual change is only possible through supportive relations. Much as our relationships teach us skills, relationships themselves are an external asset that should themselves be a goal, not simply a by-product.

\section{Final Thoughts for the Way Forward}

This book suggests that life skills should be taught to youth, but they should not be viewed as a panacea for helping youth overcome their marginalization. Youth need to understand and regulate themselves and be capable of relating to others. They especially need to be able to critically analyze the world around them and act in concert with others to achieve social change. We can help youth build the skills that they need by cultivating these same skills in their teachers and providing opportunities to build strong relationships with others.

The implication for school systems and other practitioners serving youth is that we should push for life skills to be integrated within formal primary and secondary education curriculum, just as other skills like literacy and numeracy are. Furthermore, we should do this through a more radical approach than has traditionally been adopted. We should teach critical thinking and relational skills in a way that provokes transformative change.

If we really want to advance this agenda, there are three big barriers that have been hinted at in this volume but deserve to be more fully unpacked by future research and discourse. First, governments may not actually want education to be transformative. Second, it is complex to implement life skills programs well, and to measure whether and how they work. Third, there are ethical dilemmas and risks of unintended consequences with which we must wrestle.

\section{Governments May Not Want It}

The problem with transformative change is that it seeks to upend traditional power structures. We see this come up in various chapters of the book with relation to challenging students in the classroom to give up power (see, for example, Chaps. 9 and 10). Scaling up work of this nature would pose a challenge to all those who hold privilege within society-including the very elite within government who help to define the curriculum that is taught in schools. As DeJaeghere (Chap. 4, this volume) points out, there is a "conflict between reproducing and changing norms"and the types of changes proposed under this theme may be the toughest changes to enact in school systems that seek to protect the status quo as much as they profess to change it. This may be the very reason that, as Murphy-Graham and Cohen (this 
volume) point out in Chap. 2, the terminology of "life skills" has crowded out the more threatening discourse around empowering education for girls.

What, then, is the way forward? Gentler reforms that are palatable to government may not promote the type of transformation that is encouraged by authors in this volume. On the other hand, implementation of more radical approaches outside of the government system - which is all that is feasible without government fundingmay not promote change at a scale that can truly be transformational. Perhaps the best we can settle for is incremental changes in this generation that can snowball for future generations.

\section{Life Skills Programs Are Complex to Implement and Measure}

To teach the skills that are called for in this volume requires skilled facilitators who understand these issues themselves and who are willing to confront power and engage with their students in difficult subjects that have no defined answers. Fortunately, in this book there are a number of examples of programs that have been able to do just this (see, for example, Chaps. 7 and 10). We also see, however, that more often than not programs do not contend with the more transformational elements of life skills (e.g., in Chap. 5), and this could in part be because it is so complex to do so.

A second challenge is that life skills are difficult to measure. This is made all the more complex because contextual factors matter both for how individuals develop and display life skills. As argued in both Chaps. 2 and 4, we need to measure these contextual factors as well: "Without examining features of the setting that may be contributing to or hindering children's social-emotional development, we risk merely capturing children's responses to characteristics of the environment rather than anything meaningful about their skills or capacities" (Brush et al., Chap. 3, this volume). Until we crack the question of measurement, we cannot look at life skills as an outcome of interest in and of themselves.

\section{We Must Contend with the Risk of Unintended Consequences}

The process of transformation is far from smooth. Teaching life skills in ways that enable transformative change may, at times, sit in conflict with the simple definition of life skills as the ability to do life well. To take one example, opening up a critical dialogue about gender inequality may open up girls' minds to the ways in which they are oppressed, ultimately rendering them less happy and satisfied, not more so. Getting youth to dream bigger about what they can do in life may widen the gap between their aspirations and reality, again hampering their sense of wellbeing. Trying to change norms may make it harder to succeed in a particular context, not easier. Examples like the Afar in Chap. 11 hint at ethical questions like whether it is 
better to prepare youth to live life well where they are currently situated, or to prepare them to transition and be successful in new contexts. All of these examples point to the possibility for large unintended consequences. Future research should both grapple with these ethical questions as well as seek ways to define and measure the potential for unintended consequences.

All of these challenges are well worth engaging. Youth of today are part of a generation that will grapple with rising levels of inequality, the economic and health fallout of a global pandemic, the near and present danger of climate change, and more challenges that we cannot yet imagine. They need and deserve these skills to have a fighting chance of living life well. We owe it to them to continue working to define and teach these skills, and to do it at scale.

Open Access This chapter is licensed under the terms of the Creative Commons Attribution 4.0 International License (http://creativecommons.org/licenses/by/4.0/), which permits use, sharing, adaptation, distribution and reproduction in any medium or format, as long as you give appropriate credit to the original author(s) and the source, provide a link to the Creative Commons license and indicate if changes were made.

The images or other third party material in this chapter are included in the chapter's Creative Commons license, unless indicated otherwise in a credit line to the material. If material is not included in the chapter's Creative Commons license and your intended use is not permitted by statutory regulation or exceeds the permitted use, you will need to obtain permission directly from the copyright holder. 